\title{
Competency framework of school psychologists in Vietnam schools
}

\author{
Research Article
}

\section{Hung Duy Le ${ }^{1 *}$, Mai-Lan Nguyen-Thi², Lam Khanh Tran³, Thu-Thuy Tran-Thi ${ }^{4}$}

\author{
1. Faculty of Psychology, Ho Chi Minh City University of Education, Ho Chi Minh City, Vietnam, \\ 2. Institute of Psychology, Vietnam Academy of Social Sciences, Hanoi, Vietnam, \\ 3. Vietnam Association of Certified Public Accountant, Ho Chi Minh City, Vietnam, \\ 4. Hoa Thien Ly Kindergarten, Ho Chi Minh City, Vietnam.
}

\begin{abstract}
A competency framework points out the requisite skills and knowledge of a particular occupation. A competence framework enables institutions to easily identify areas where remedial training may be required; thereby training quality and ultimately public safety could be improved also. This study was conducted to build up a competency framework for school psychologists in Vietnamese. 91 school psychologists, lecturers, and psychologists from Ho Chi Minh City, Binh Duong Province, Long An Province, Vinh Long Province, Can Tho Province in Vietnam participated in the survey process. The findings of our study showed that the competency framework for school psychologists in Vietnam includes three main components: (1) professional knowledge, (2) counseling skills, and (3) attitude and moral qualities.
\end{abstract}

Key Words: Vietnamese, Competency framework, School psychologist, Counseling psychology.

\section{Introduction}

In the beginning of the $21^{\text {st }}$ century, a great number of element schools, secondary schools and high schools in Ho Chi Minh City (Vietnam) started to create school counseling programs for their students, with support from Vietnamese and foreign counselors (Ngo, 2007). However, school counseling in Vietnam at that stage did not reach the professional level (Do, 2006; Le, 2009). A school psychologist needs to be knowledgeable and flexible so that he/she could come up with the most acceptable and innovative solutions for problems of the school while he/she must well handle their professional tasks (1).

A competency framework points out the requisite skills and knowledge of a particular occupation. It offers a collection of the indispensable skills, and the combination of these, that jointly contributes to successful job performance (1). Rodriguez, Patel, Bright, Gregory, and Gowing (2002) defined "competencies" as an assessable pattern of an individual's knowledge, skills, professional qualifications, behaviors, and other necessary characteristics to properly execute job responsibilities or occupational duties. Competency standards represent the bedrock of any profession's credibility. A competence framework enables institutions to easily

\section{* Corresponding Author:}

\section{Hung Duy Le}

Faculty of Psychology,

Ho Chi Minh City University of Education,

280 An Duong Vuong Street, Ward 4, District 5,

Ho Chi Minh City, 72706, Vietnam.

Email Id: hungld@hcmue.edu.vn identify areas where remedial training may be required; thereby training quality and ultimately public safety could be improved also (19). Well understanding of competencies supports people to identify, evaluate, and deal with their incompetence (6). Psychology researchers and educators have introduced different competency models for Psychologist in general; such as a cube model, proposed by Rodolfa et al. (2005), includes third dimension (six foundational competencies, six functional competencies and stages of professional development); another version of the "cube model" which is easier to be applied to life and more simple than the original one (6); the interlocking rings model and the Pyramid Model (10); competency framework for practicing psychologists (3); psychology practice in Australia (19). Noticeably, the competency framework for psychology practice of ASPPB (2010) stated six main domains including scientific knowledge, evidence-based decision making, cultural and interpersonal competence, ethics, assessment, and supervision. Years later, Von Treuer and Reynolds (2017) developed a competency model in the practice of psychology which reported four core competencies and two meta-competencies. Those core competencies include determining client needs, designing evidencebased interventions, implementing interventions, and evaluating outcomes; and two meta-competencies are practicing professionally and communicating, collaborating effectively.

In Vietnam, Tran (2009) explored six psychology counseling skills which respectively are listening, questioning, empathizing, responding, explaining, silence handling, communicating, information delivery, expressing the self, and coping. In the first (2009) international conference on school 
psychology counseling in Vietnam, all psychologists participating agreed that school psychologists must be professionally trained in educational knowledge, psychology and practical counseling skills, and simultaneously, be equipped with some practicing social work knowledge and skills. Specifying the professional standards that the school psychologists must pursue is not only a fundamental background for them to meet the requirements of the new General educational program, but also a advantageous condition where students are more likely to seek help from counseling service. Moreover, the lack of a standard competency framework for school psychologists can be a barrier in promoting their educational roles. At the same time, it can hardly create a legal corridor to protect school psychologists' benefits. Confronting the need for school counselors in Vietnam $(12,16)$ as well as those certain issues, developing a competency framework for school psychologists is a vital mission. However, there has been no study engaged in competency framework for school psychology counselors in Vietnam so far. To bridge this gap, we conduct this study in order to explore and develop a competency framework for school psychologists in Vietnam.

\section{Methods \\ Participants}

The school psychologists were selected from secondary schools and high schools in Ho Chi Minh City, Binh Duong Province, Long An Province, Vinh Long Province, Can Tho Province by random sampling method; and the lecturers as well as psychologists majoring in Psychology, Educational psychology and Social work were randomly selected from universities in Ho Chi Minh City.

Ninety-one school psychologists, and lecturers as well as psychologists from the universities having Psychology Department took part in this study, including 68 school psychologists (accounted for $74.7 \%$ and 23 lecturers as well as psychologists from the universities (accounted for 25.3\%). The survey process started from August 2019 and end in September 2019. The ethics committee approved this study at the Ho Chi Minh City University of Education, Vietnam. We obtain written informed consent from all participants.

Within 68 school psychologists from secondary schools and high schools, $48,5 \%$ of them have up to 5 years of experience in working as a school psychologist $(\mathrm{n}=33), 36.8 \%$ of them have worked in this position for 6 - 10 years $(n=25)$ and $14.7 \%$ of them have 11 15 years of experience $(n=10)$. Within 23 lecturers and psychologists from universities, $17.4 \%$ of them have up to 5 years of experience in working $(n=4), 39.1 \%$ of them have worked in those positions for $6-10$ years (n $=9), 26.1 \%$ of them have $11-15$ years of experience $(\mathrm{n}$ $=6$ ) and $17.4 \%$ of them have worked from 16 to 20 years in those positions $(n=4)$.

\section{Measurement}

The questionnaire is designed for a sample who are directly engaged in school psychological counseling activities at schools and lecturers who are teaching in
Psychology departments of universities. This questionnaire is built through the following stages:

- Fist stage: Based on the literature review of the study, we designed an open-ended questionnaire related to competency requirements. After that, we conducted a trial survey of 20 school psychologists to collect necessary information for the official questionnaire.

- Second stage: The official questionnaire is designed based on the necessary requirements of competency regarding those aspects: current general situation of psychological supporting activities, evaluation of competency; evaluation of the necessity of the components of their professional knowledge.

The Statistical Package for the Social Sciences (SPSS) version 20 was used for data analyses. The coding procedure was performed as follow: $1=$ unnecessary, $2=$ not necessary, $3=$ neutral, $4=$ necessary, $5=$ very necessary. For the purpose of transforming the discrete values into ranks, distance value was calculated as (Maximum - Minimum) $/ \mathrm{n}=$ $(5-1) / 5=0.8$ (9). Therefore, the meanings of the rankings were judged as unnecessary $(1.0-1.8)$, not necessary $(1.8-2.6)$, neutral $(2.6-3.4)$, necessary $(3.4$ $-4.2)$, very necessary $(4.2-5.0)$.

\section{Procedure}

Participants signed the written consent, which explain and guarantee their rights in the completion of the study, after their agreement to take part in the survey. In the beginning, the participants are required to complete the General Information form, including their professional training and years of experience. After that, the instructions of filling the questionnaire were delivered to the participants do that they fully understand the questionnaire. All school psychologists, lecturers and psychologists were informed about the information security commitment. They were asked to complete each question based on their own experience and knowledge.

\section{Results}

School psychologists' professional competency and psychological support activities in schools in

\section{Vietnam}

\section{- Psychological support activities in schools in Vietnam}

\begin{tabular}{|c|c|c|}
\hline $\begin{array}{l}\text { Psychological support activities in } \\
\text { schools }\end{array}$ & $\mathbf{N}$ & $\%$ \\
\hline Psychology counseling & 79 & 86.8 \\
\hline Career consulting & 78 & 85.7 \\
\hline $\begin{array}{l}\text { Psychology assessment including } \\
\text { psychological tests on mental health, } \\
\text { career, personality }\end{array}$ & 64 & 70.3 \\
\hline School psychological backup activities & 8 & 8.8 \\
\hline $\begin{array}{l}\text { Other psychological support activities: } \\
\text { crisis intervention; mental health care; } \\
\text { teaching soft skills }\end{array}$ & 3 & 3.3 \\
\hline
\end{tabular}


The table 1 indicates that three most common psychological support activities in schools reported by the participants are respectively Psychology counseling (86.8\%), Career consulting (85.7\%), and Psychology assessment including psychological tests on mental health, career, personality $(70.3 \%)$.

\section{Figure 1. Evaluate the effectiveness of psychology} counseling activity in schools

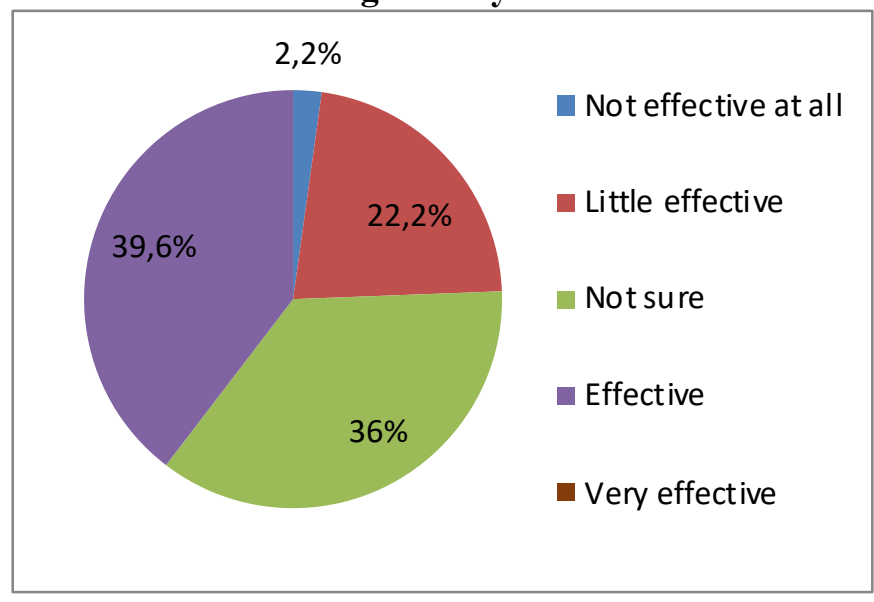

Findings from Figure 1 shows that while only $39.6 \%$ of the total participants evaluated the psychology counseling activity in school effective, $36 \%$ of them reported a heritage attitude towards the effectiveness of this activity and $22.2 \%$ of them thought it was ineffective. Remarkably, none of the participants fully believed in the effectiveness of psychology counseling activity in schools.

\section{- Evaluate the components of school psychologists' professional competency}

Table 2. The components of school psychologists' professional competency

The components of school psychologists' professional competency

Professional knowledge

\begin{tabular}{|l|l|l|}
\hline $\mathbf{N}$ & $\mathbf{\%}$ \\
\hline 84 & 92.3 \\
\hline 83 & 91.2 \\
\hline 82 & 90.1 \\
\hline
\end{tabular}

Attitude towards career

Other components: Self-improvement capacity; Environment and conditions for updating professional knowledge; Relationship with other professionals;

Working experience

Boosting school psychologists' competency is considered one of the most indispensable mission in order to improve the quality of psychology counseling activity in schools. The very first step to boost their competency is to specify its components. According to findings from Table 2, the importance of three main components merely shared the same proportion (approximately above 90\%). Besides, $17.6 \%$ of the participants voted for other components, which are known as supporting factors for the three main components.
School psychologists' perception on main contents in building the professional competency framework

- School psychologists' perception on their requisite training programs and degrees

Table 3. Requirements on training programs and degrees of school psychologists

Requirements on training programs and degrees of school psychologists

Mean SD

Be professionally trained in Psychology,

Educational psychology, Social work

$\begin{array}{ll}4.52 & 0.75\end{array}$

Need to hold not only Bachelor degree but also Master degree

$3.61 \quad 0.92$

Take part in training programs to enhance their own knowledge and skills

$4.46 \quad 0.71$

Complete of $6-12$ months practicum under supervision of a registered psychologist before officially work as a school psychologist

Master knowledge of Development psychology and Educational psychology Master the professional psychological practical processes, Ethics in psychological practice, and information security commitment

Apply scientific approaches to problems related to children and adolescents' psychological development including mental health, psychological assessment, psychological intervention

Have proper knowledge and skills in cognitive assessment and intervention

Have proper knowledge and skills in behavioral assessment and intervention Provide psychological interventions for personal problems

Provide mental health educational programs in schools

Provide expert advice about the procedures in school such as students manage, school discipline, and peer support activities

Total

$4.21 \quad 0.86$

4.53

$4.10 \quad 0.86$

$4.04 \quad 0.96$

$\begin{array}{ll}4.34 & 0.77\end{array}$

$\begin{array}{ll}4.09 & 0.88\end{array}$

\begin{tabular}{l|l}
4.13 & 0.92
\end{tabular}

4.25

0.64

Table 3 represents that all items have the mean scores above 3.4, indicating that schools' psychologists rated those requirements as all important. Within 12 requirements related to school psychologists' training programs and degrees, the top three requirements rated the most necessary were respectively Master knowledge of Development psychology and Educational psychology $(\mathrm{M}=4.64, \mathrm{SD}=0.70)$, Master the professional psychological practical processes, Ethics in psychological practice, and information security commitment $(\mathrm{M}=4.53, \mathrm{SD}=0.76)$, and $B e$ professionally trained in Psychology, Educational psychology, Social work $(\mathrm{M}=4.52, \mathrm{SD}=0.75)$.

Noticeably, need to hold not only bachelor's degree but also Master degree was rated the least necessary requirement among 12 requirements $(\mathrm{M}=$ 3.61, SD = 0.92); and followed by Have proper knowledge and skills in behavioral assessment and intervention $(\mathrm{M}=4.04, \mathrm{SD}=0.96)$, and Provide mental health educational programs in schools $(\mathrm{M}=4.09, \mathrm{SD}$ $=0.88$ ). 
- School psychologists' perception on their requisite professional skills

Table 4. School psychologist's' professional skills School psychologists' professional skills $\quad$ M $\quad$ SD Support students on learning methods - career guidance

$4.06 \quad 0.66$

Educate soft skills

$4.18 \quad 0.66$

Supply supporting activities, counseling activities based on the students' need

4.240 .66

Conduct psychological assessment

$4.13 \quad 0.69$

Have adequate knowledge of the law and the ability to report, coordinate

Have basic counseling skills (listen, observe, respond, question, build a counseling relationship, non-verbal communicate)

Have specific counseling skills (pinpoint students' strengthen, sum up the information, develop and organize intervention programs for psychological disorder)

Carrer attitudes of school psychologists

4.540 .66

In the Table 4, most of the items were considered as very necessary (their mean scores are above 4.2). The findings also point out that Have specific counseling skills was ranked the most indispensable requirements among all items $(\mathrm{M}=4.66$, $\mathrm{SD}=0.79)$; followed by Career attitudes of school psychologists $(\mathrm{M}=4.54, \mathrm{SD}=0.66)$ and Have basic counseling skills $(\mathrm{M}=4.44, \mathrm{SD}=0.68)$. Among eight professional competencies surveyed, the participants rated Support students on learning methods - career guidance as the least important requirement $(\mathrm{M}=4.06$, $\mathrm{SD}=0.66$ ).

\section{- School psychologists' perception on their requisite moral qualities and lifestyle}

\section{Table 5. Moral qualifies and lifestyle} Moral qualities and lifestyle M SD

Moral qualities of school psychologists $4.43 \quad 0.53$

Lifestyle politics and lifestyle ethics

$4.38 \quad 0.56$

Both requirements as regards school psychologists' requisite moral qualities and lifestyle were reported as really important for them to well achieve. Particularly, moral qualities including strictly practicing professional ethics; honesty and sincerity; non-judgmental acceptance, love, and respect; responsibility; set the boundaries in a counseling relationship.

\section{Discussion}

The study pointed out that there was a proper evaluation of the importance and role of psychological support activities, that is also an important step to organize those activities to meet students' needs. However, school psychological backup activities were under evaluated while Circular 31/2017/TT-BGDDT (Art.3(1) Purpose of psychological counseling for students) states that preventing, supporting and intervening (when necessary) for students facing psychological difficulties in order to find appropriate solutions and minimize negative impacts contributes to building a safe, healthy, and friendly educational environment. Psychological backup activities are one of the most vital purposes of school psychological counseling program. The result of school psychologists' perspective on effectiveness of counseling activities in schools reflects a current general situation of those activities which have not been paid attention to and invested properly. Knowledge, skills, and attitudes are the components that mainly constitute the competency of school psychologists as once be discussed in the study of Bourg et al. (1987).

In order to meet the competency requirements, school psychologists need to be professionally trained in Psychology, Educational psychology, Developmental psychology, or Social work so that they can firmly grasp the psychological characteristics of each age to have an appropriate approach. In addition, school psychologists also need to participate in training/ retraining programs to improve their knowledge and skills. School psychologists need to have proper knowledge of psychological assessment to have appropriate interventions, and detail information on students' psychological problems. In general, the participants' perception on psychological assessment reveals that they have an appropriate attitude towards psychological counseling in schools. In addition to the requisite professional knowledge to do well in counseling for students, school psychologists also need to understand the law and handle issues related to working processes.

\section{Conclusion}

To build a competency framework for school psychologists, the experts need not only the list of requirements related their capacity, professional ethical qualities but also need to consider the school psychologists' lifestyle. If competency requirements are the key to meeting job requirements, then school psychologists' qualities help shape the job's value.

\section{Acknowledgement}

The authors acknowledge the schools' Principles and school psychologists, lecturers, psychologists in Vietnam, who supported us in gathering the field data for this research.

\section{Funding}

This research is funded by Ho Chi Minh City University of Education under grant number CS.2018.19.49

\section{Conflicts of interest}

There are no conflicts of interest.

\section{Data and materials availability}

All data associated with this study are present in the paper. 


\section{Reference}

1. Baczyńska, A. K., Rowiński, T., \& Cybis, N. (2016). Proposed core competencies and empirical validation procedure in competency modeling: confirmation and classification. Frontiers in Psychology, 7, 1-13.

2. Bennett, V. D. (1970). Who is a school psychologist?(And what does he do?). Journal of School Psychology, 8(3), 166-171.

3. Boards, A. o. S. a. P. P. (2010). Study of the practice of licensed psychologists in the United States and Canada. Retrieved from https://cdn.ymaws.com/ w w w . a s p p b.net/resource/res m g r/ eppp 2/2010 asppb_final practice_an.pdf

4. Bourg, E. F., Bent, $\bar{R}$. J., Callan, J. E., Jones, N. F., McHolland, J. E., \& Stricker, G. E. (1987). Standards and evaluation in the education and training of professional psychologists: Knowledge, attitudes, and skills. Paper presented at the Mission Bay Conference, Dec, 1986, Mission Bay, San Diego, CA, US.

5. Do, V. B. (2006). The reality of counseling services in Ho Chi Minh City. . Paper presented at the Conference on Building and Developing a School Counseling Network., Hanoi, Vietnam.

6. Gonsalvez, C. J., \& Calvert, F. L. (2014). Competency-based models of supervision: Principles and applications, promises and challenges. Australian Psychologist, 49(4), 200-208.

7. Kaslow, N. J., Rubin, N. J., Forrest, L., Elman, N. S., Van Horne, B. A., Jacobs, S. C., . . . Dollinger, S. J. (2007). Recognizing, assessing, and intervening with problems of professional competence. Professional Psychology: Research and Practice, $38(5), 479$.

8. Le, P. (2009). Gap analysis of Vietnamese student counselors' knowledge competencies. .

9. Malhotra, N., Hall, J., Shaw, M., \& Oppenheim, P. (2006). Marketing research: An applied orientation: Pearson Education Australia.

10. Nash, J. M., \& Larkin, K. T. (2012). Geometric models of competency development in specialty areas of professional psychology. Training and Education in Professional Psychology, 6(1), 37-46.

11. Ngo, M. U. (2007). Tham vấn tâm lý học đương: Lịch sư và phát triển [School counseling: History and development]. Paper presented at the Psychological Support for Students, Bienhoa, Vietnam.

12. Nguyen-Thi, D.-M., Huynh, V. S., \& Tran-Chi, V.L. (2020). Loneliness, Stress, Self-esteem, and Deception among Adolescents. Journal of Human Ecology, 70(1-3), 118-123.

13. Nguyen, T. H. P. (2009). Tham vấn học đường và nhu cầu tham vấn của họ sinh trung hoc phổ thông [School counseling and the counseling need of high school students]. Paper presented at the need, orientation and training of school psychology in Vietnam, Hanoi, Vietnam.

14. Rodolfa, E., Bent, R., Eisman, E., Nelson, P., Rehm, L., \& Ritchie, P. (2005). A cube model for competency development: Implications for psychology educators and regulators. Professional Psychology: Research and Practice, 36(4), 347-354.

15. Rodriguez, D., Patel, R., Bright, A., Gregory, D., \& Gowing, M. K. (2002). Developing competency models to promote integrated human resource practices. Human Resource Management: Published in Cooperation with the School of Business Administration, The University of Michigan and in alliance with the Society of Human Resources Management, 41(3), 309-324.

16. Terjesen, M. D., Kassay, K. S., \& Bolger, M. (2008). Developing the profession of school psychology in Vietnam. Communique, 37(2), 1-8.

17. Training, V. M. o. E. (2017). Circular 31/2017/TTBGDDT. Retrieved from https://moet.gov.vn/vanban/vanban/Pages/chi-tiet-van-ban.aspx? ItemID $=1269$

18. Tran, T. M. D. (2009). Giáo trình tham vấn tâm lý [Counseling Psychology Textbook]. Hanoi: Vietnam National University Press.

19. Von Treuer, K. M., \& Reynolds, N. (2017). A competency model of psychology practice: Articulating complex skills and practices. Paper presented at the Frontiers in Education. 